\title{
What's in a Name? \\ Analyzing the Evolving Concept of Broadband
}

\author{
Dr. Mark A. Jamison \\ Public Utility Research Center \\ University of Florida \\ Dr. Janice A. Hauge* \\ Department of Economics \\ University of North Texas
}

Version date: October 14, 2009

\begin{abstract}
In this paper we examine methods of broadband measurement, with particular emphasis on techniques for determining whether broadband availability and adoption are optimal. We identify four methods for assessing whether the existing level of investment is the most advantageous. These include tests for market power, use of market surveys, examination of production functions and prices, and analysis of shadow prices. All of these methods utilize broadband measures that one would find in operators' service offerings.
\end{abstract}

Key Words: Broadband, Productivity, Shadow Prices

This is a work in progress. Please do not cite or quote without permission of the authors. For information or to provide comments on this report, please contact Dr. Mark A. Jamison, Director, PURC, University of Florida, PO Box 117142, Gainesville, FL 32611-7142, +1.352-392-6148, jamisoma@ @ufl.edu.

\footnotetext{
* The authors are Director, Public Utility Research Center (PURC), University of Florida, and Associate Professor, Department of Economics, University of North Texas, respectively. The authors would like to thank Mircea Marcu and George Ford for their contributions to earlier work that prompted this research. The authors are solely responsible for all content, errors, and omissions.
} 


\section{Introduction}

"Parts is parts." is the laugh line from a once famous Wendy's commercial about the fast-

food company's chicken sandwich. ${ }^{1}$ The message was that Wendy's cared about the quality of the chicken in its sandwiches, but other fast-food burger places were indiscriminant in their meat choices.

Perhaps we are in a similar situation with broadband. On the one hand, entities like the Organization for Economic Cooperation and Development (OECD) offer highly aggregated broadband indicators that ignore differences in technologies, consumer uses, bandwidths, geography, and population; in other words, access is access. In contrast, organizations like Connected Nation, a broadband mapping corporation in the United States, gather detailed data on broadband locations and technologies, although some details are kept proprietary.

Broadband measurement has become an important topic for policy makers, telecommunications stakeholders, and researchers. The economic importance of broadband is well established and numerous studies have gauged its impacts (Holt and Jamison 2008). This economic importance has contributed to broadband's political importance. The OECD broadband penetration rankings frequently are cited in the media and by government officials, including Barak Obama during his run for the presidency of the United States. As a candidate, he followed the traditions of politicians from countries with low broadband penetration rankings and concluded that the government needs to play an activist role in broadband deployment and adoption. This resulted in several billion taxpayer dollars being allocated to a variety of projects. Similarly, in Australia broadband deployment was an issue in recent national elections, resulting

\footnotetext{
${ }^{1}$ The commercial is available on You Tube at http://www.youtube.com/watch?v=OTzLVIc-O5E.
} 
in what could be a US $\$ 31$ billion scheme to build a national broadband network in which the government is the primary, if not sole owner. ${ }^{2}$

Despite the importance of the topics of broadband deployment, adoption, and impact, there is much that we do not know about how various broadband technologies differ in their effectiveness and value. For example, for fixed broadband services, customers and operators can choose digital subscriber line (DSL), fiber to the home (FTTH), or cable. Some countries have focused on fiber optics and others on wireless. For wireless broadband the choices include Wi-Fi, third generation mobile (3G), and WiMAX. Other countries have remained basically technology neutral, although it is difficult to treat fixed and wireless the same because of their different technical needs. For example, wireless needs radio spectrum, equipment licensing, and towers, while fixed needs access to conduit, rights of way, buildings, and sometimes shared network facilities. Technologies vary in their bandwidth availability, accessibility, and ease of use. Even within the technologies, service providers offer different bandwidths and the bandwidths that customers experience are sometimes different than the bandwidths advertised. To address this discrepancy, the company epitiro, for example, offers isposure, ${ }^{3}$ a software package that assesses actual performance of customer broadband connections.

Not only are broadband technologies heterogeneous, but there are differences in how governments and other organizations measure broadband. As stated above, the OECD aggregates its broadband subscription data at the national level and permits inconsistency in across countries

\footnotetext{
${ }^{2}$ See "Broadband Promises Crash Aussie Election,” The Inquirer, 18 June 2007, http://www.theinquirer.net/inquirer/news/601/1034601/broadband-promises-crash-aussie-election; and "Australia to Build \$31 Billion Broadband Network,” The New York Times, April 26, 2009, http://dealbook.blogs.nytimes.com/2009/04/07/australia-to-build-31-billion-broadband-network/.

${ }^{3}$ See http://www.epitiro.com for information on epitiro, and http://www.isposure.com/index.htm for information on how isposure software analyzes consumers' line speed, web-browsing speed, ping times, and DSN times, among other capabilities.
} 
and over time regarding when data are collected, how they are collected, and how business broadband is reflected. (Wallsten 2008) A recent study of broadband in Portugal used household survey data provided by ANACOM, the national telecommunications regulator, but that data was limited in that it identified households by geographic region designated at the NUTS 1 level, and even though it identified access technology, it did not specify bandwidths and pricing plans. ${ }^{4}$ (Hauge, Jamison, and Marcu 2009) In the United States, until recently the federally-prescribed data collection methodology on deployment and subscribership aggregated data at the zip code level. The U.S. Federal Communications Commission (FCC), which is responsible for the U.S. data collection, is revising its methodology to obtain data of a more granular nature geographically and to disaggregate measurements by detailed speed tiers and technology platforms.

In this paper we address this issue of broadband measurement. We find that, as a technical issue, the parameters of broadband measurement vary with the reasons for measurement. For most uses, measurement parameters should correspond to those that customers consider when deciding whether to purchase broadband and if so, which broadband offering to purchase. Regarding broadband indices, we find that the indices are mostly misleading because they implicitly assume uniform weightings, so that for example the OECD ranking simply sums all DSL, cable, and fiber/LAN connections of all speeds. The weights are necessary to permit the summation of inherently heterogeneous data, but as a result they hide the diversity of broadband offerings and the differences in the effectiveness of various technologies to add value for

\footnotetext{
${ }^{4}$ NUTS stands for Nomenclature of Units for Territorial Statistics, the statistical regions of Europe as defined by the European Union. NUTS levels are defined in terms of minimum and maximum population sizes, where NUTS 1 indicates a geographic region with $3 \mathrm{~m}$ to $7 \mathrm{~m}$ residents. Additional information is available at: http://ec.europa.eu/eurostat/ramon/nuts/home_regions_en.html.
} 
economic development, job growth, education, health care, and the like. Finally, we find that oftentimes the ultimate questions for policy makers and sector regulators are whether limited broadband availability is an economically unjustifiable constraint on outcomes of interest, such as economic development, and what is the extent of uneconomic constraints on broadband availability. We suggest an approach to answer these questions.

The remainder of this paper proceeds as follows. In the next section we provide a discussion of why broadband is measured and how the reason for measurement informs measurement approaches. In the third section we address the specifics of measurements that should be taken and the appropriate levels of aggregation. We then examine how broadband indicators are aggregated and used as benchmarks for policy makers. In the fifth section we describe techniques for determining whether broadband penetration is a constraint for a country or region. The last section is the conclusion.

\section{Reasons for Measuring Broadband}

There are many reasons for measuring broadband and they can be grouped in several ways. For our purposes, we identify four categories of reasons for measuring broadband. The first category of reasons comprises simple monitoring of deployment, technologies, adoption, and the like. This monitoring work is often done by sector regulators, who serve as government experts on the sector and interact with academia, consultants, other government entities, and industry. (Vibert 2007, pp. 25-26, 42-48) As the governments' experts, they inform politicians, other governmental entities, and the public. The monitoring efforts not only serve as a source of data for others, but also serve to ensure that the sector agency itself is sufficiently informed and expert to make valid decisions about sector regulation. Examples of measuring broadband for 
monitoring include efforts by the FCC and ANACOM. The FCC's Trends in Telephone Service $e^{5}$ reports semiannual numbers of lines using asymmetric digital subscriber line (ADSL), symmetric digital subscriber line (SDSL), traditional wireline, cable modem, fiber, satellite, fixed wireless, mobile wireless, and power line, and reports whether the lines are residential or other, and the broadband capacity (categories include $200 \mathrm{kbps}$ to $2.5 \mathrm{mbps}, 2.5$ to $10 \mathrm{mbps}, 10$ to $25 \mathrm{mbps}, 25$ to $100 \mathrm{mbps}$, and greater than or equal to $100 \mathrm{mbps}$ ), by state. Numbers are aggregated to denote household penetration and to differentiate between urban and rural.

ANACOM’s recent survey, titled "Inquérito ao Consumo dos Serviços de Comunicações Electrónicas” or survey of consumption of electronic communication services (ICSCE), was conducted by TNS-Euroteste for ICP-ANACOM in 2008. Those surveyed were individuals 15 years of age or older, living in a residential household in Portugal. The survey asks "What type of Internet connection do you use at home?” Possible responses included: modem or ISDN, ADSL or other XDSL access, cable, mobile phone or PDA with broadband Internet connection, phone connected to Internet through narrowband, broadband wireless connections other than mobile phone and PDA, data transmission cards, and other or do not know.

Reporting also might be performed to inform the public about service offerings. For example Ofcom, the independent regulator and competition authority for communication industries in the $\underline{\mathrm{UK}}$, offers a portal that allows consumers to identify where mobile broadband is available from specific providers. ${ }^{6}$

Our second category of reasons for measuring broadband is for benchmarking. The most famous of these benchmarking efforts is the OECD broadband penetration rankings in which the

\footnotetext{
${ }^{5}$ FCC, 2008, “Trends in Telephone Service,” http://hraunfoss.fcc.gov/edocs_public/attachmatch/DOC284932A1.pdf, accessed September 5, 2009.

${ }^{6}$ See http://www.ofcom.org.uk/consumer/2009/08/mobile-broadband-coverage-checker/, accessed September 5, 2009.
} 
organization ranks countries in terms of their per-person broadband connections by summing DSL, cable, fiber, certain wireless access (satellite, LMDS, MMDS, and fixed WiMAX, but not 3G mobile technologies and $\mathrm{Wi}-\mathrm{Fi}$ ), and broadband over power lines, and dividing by population. $^{7}$ Another benchmarking approach is used by The Information Technology \& Innovation Foundation (ITIF) in which the organization ranks countries on a composite score of household penetration, average download speed, and price. ${ }^{8}$ Ford et al. (2008) performed a cross country benchmarking analysis of broadband penetration using Stochastic Frontier Analysis. The study found that economic and demographic endowments explain 91 percent of the variation in broadband subscriptions across OECD countries and that most countries' penetration levels are very near what the model would predict, indicating that there are few if any market or policy failures.

Analysis and planning is our third category of reasons for broadband measurement. This is a step beyond the simple data gathering and reporting that characterize the monitoring effort. Analysis and planning includes interpreting the data to draw conclusions about sector performance and trends. At one level analysis and planning is a general exercise not tied to a specific issue or decision and represents only a minor step beyond reporting. For example the Florida Public Service Commission annually publishes a report on the status of

\footnotetext{
${ }^{7}$ See for example the OECD press release at http://www.oecd.org/document/4/0,3343,en_2649_34225_42800196_1_1_1_1,00.html, accessed September 5, 2009. See also the OECD’s criteria at http://www.oecd.org/document/46/0,3343,en_2649_34225_39575598_1_1_1_1,00.html, accessed September 5, 2009.

${ }^{8}$ See http://www.itif.org/files/2008BBRankings.pdf, accessed September 5, 2009.
} 
telecommunications competition in Florida that includes an analysis of technology trends and broadband development, and what such trends and development might mean for the state. ${ }^{9}$

At another level, agencies conduct analyses to make decisions about specific issues. Ofcom used its data gathering to inform its decisions on policies for broadband and next generation networks. The analyses included investigations into service provider investment plans, potential revenues, market competition and price performance, international comparisons of drivers of technology choices, next generation network rollouts and services, and broadband availability and penetration. ${ }^{10}$ Both the FCC and Ofcom have used their monitoring data and other data gathering to investigate issues of market power. The FCC has launched a broadband planning initiative that couples its own data gathering with the opinions and information of various stakeholders and advocacy groups. ${ }^{11}$ Connected Nation uses its data gathering to assist communities in their planning for broadband utilization and development, and governments in their broadband policy development.

Our fourth category of reasons for measuring broadband is for statistical studies of broadband penetration and impact. These include studies of drivers of broadband supply (e.g., Bauer, Kim and Wildman 2003; Cava-Ferreruela and Alabau-Muňoz 2006; and Lee and Marcu 2008), demand drivers (e.g., Rappoport et al. 2001; Prieger 2003; Cardona, Schwarz, Yurtoglu and Zulehner 2007; and Hu and Prieger 2008), and economic impacts (e.g., Ford and Koutsky 2005; Gillett et al. 2006; and Crandall et al. 2007).

\footnotetext{
${ }^{9}$ Florida Public Service Commission. 2009. "Report on the Status of Competition in the Telecommunications Industry.” Available at http://www.floridapsc.com/publications/pdf/telecomm/20090731MasterComp.pdf, accessed September 5, 2009.

${ }^{10}$ Ofcom, 2007, "Future Broadband: Policy Approach to Next Generation Access.” Available at http://www.ofcom.org.uk/consult/condocs/nga/future_broadband_nga.pdf. Accessed September 5, 2009. Dougal Scott presentation on "Future Broadband: Policy Approach to Next Generation Access." Available at http://www.ofcom.org.uk/consult/condocs/nga/slides.pdf. Accessed September 5, 2009.

${ }^{11}$ See FCC “National Broadband Plan” at http://www.broadband.gov/, accessed September 5, 2009.
} 


\section{Technical Measurement}

In this section we address the technical parameters of measuring broadband. We begin by explaining why the parameters should correspond to those used by customers when purchasing broadband. We then examine two approaches for determining whether some parameters can be aggregated.

For studies of customer impacts and choices broadband should be measured in the same way that customers see broadband when making choices. That is to say if service providers present a customer with choices among modes of access, e.g., DSL, cable, and WiMAX, and the customer has preferences and makes choices based on those preferences, it is important to differentiate the technology choices in the data that is gathered. Otherwise, the unstated assumption is that the customer views all technologies as perfect substitutes and makes choices simply on price. Some customers may indeed view broadband technologies in this way, although it is unlikely given the studies cited above, but one cannot know if the technologies are perfect substitutes without utilizing data that is disaggregated by the technology and bandwidth choices that customers make.

To illustrate this analytically for business and government customers of broadband, consider a Cobb-Douglas production function of $Y=L^{\alpha} D^{\delta} M^{\mu}$, where $Y$ is the output produced using three inputs: Labor (L), DSL (D), and cable modem (M). The output is estimated using a log transformation, namely

$$
\ln Y=\alpha \ln L+\delta \ln D+\mu \ln M+\varepsilon
$$

where $\varepsilon$ is the error term. If we were to aggregate DSL and cable modem into a single variable, $B$, (1) would become

$$
\ln Y=\alpha \ln L+\beta \ln B+e .
$$


Comparing (1) and (2), we can see that

$$
\beta=\frac{\delta \ln D+\mu \ln M+\varepsilon-e}{\ln D+\ln M} .
$$

(3) reduces to an identity (i.e., $\beta=\beta$ ) only if $\delta=\mu$, i.e., DSL and cable modem are perfect substitutes. Otherwise, $\beta$ will vary with the mix of DSL and cable modem, implying that DSL and cable modem should not be combined into a single broadband measure unless $\delta=\mu$.

Following Michael and Becker (1973), we can apply a similar analysis to consumer purchases of broadband. Consumers seek to maximize utility by purchasing market goods and services subject to budget constraints, and then convert these market products into consumption commodities subject to a time constraint and consumer abilities. Michael and Becker show that the optimal solution for an individual consumer is to acquire and use market products at the point where the ratio of 1 ) the marginal utility resulting from a market product being used to produce a consumption commodity, to 2) the marginal utility resulting from a market product being used to produce a different consumption commodity, is equal to the ratio of the market products prices. Adapting Michael's and Becker's equation (11) to our needs, have

$$
\frac{M U_{i} \cdot M P_{i D}}{M U_{j} \cdot M P_{j M}}=\frac{p_{D}}{p_{M}} .
$$

For all $i$ and $j$, where $M U_{i}$ is the marginal utility received from consumption commodity $i$ for which broadband is an input; $M P_{i k} k=D, M$, is the marginal product of broadband product $k$ in producing consumption commodity $i$; and $p_{k}$ is the price of broadband product $k$. The broadband products are perfect substitutes if their marginal products are equal and their prices are equal. This implies that DSL and cable modem should not be combined into a single broadband measure unless $M P_{i D}=M P_{i M}$ for all $i$. 
(3) and (4) form the foundation for our conclusion that the technical parameters of broadband measurement should be those that customers use when making purchasing decisions. We used DSL and cable modem for our analysis, but we could have chosen any dimensions of broadband that customers can choose. Such dimensions should not be ignored unless they do not matter to customers. Likewise, they should not be included unless customers can choose them.

What are the technology choices customers make? Consider the Internet plans offered by Verizon. ${ }^{12}$ The company offers three plans for DSL-based Internet access: a Starter Plan with download up to 1 Mbps and upload up to 384 Kbps; a Power Plan with download up to 3 Mbps and upload up to $768 \mathrm{Kbps}$, and a Turbo Plan with download up to $7.1 \mathrm{Mbps}$ and upload up to 768 Kbps. The last two plans include free Wi-Fi access. The company also offers fiber access through its FiOS service. ${ }^{13}$ There are three plans: a Fast plan with download up to 15 Mbps and upload up to 5 Mbps; a Faster plan with download up to 25 Mbps and upload up to $15 \mathrm{Mbps}$; and a Fastest plan with download up to $50 \mathrm{Mbps}$ and upload up to $20 \mathrm{Mbps}$. The last two plans both include free Wi-Fi access. Similar spot checks of service providers indicate that customers can choose the technologies typically measured - DSL, cable, fiber, satellite, Wi-Fi, 3G, 4G, and WiMAX - and can choose among various speeds. The speeds are not uniform across providers, but clearly customers make speed choices, so there is a need to collect data on speed. Beyond those technical parameters, it does not appear to be necessary to collect other details, such as ADSL versus SDLS, as are collected by the OECD.

The foregoing discussion demonstrates that broadband is at least a heterogeneous product; it may also be multiple products. As a heterogeneous product, various broadband

\footnotetext{
${ }^{12}$ See http://www22.verizon.com/Residential/HighSpeedInternet/Plans/Plans.htm, accessed September 5, 2009.

${ }^{13}$ See http://www22.verizon.com/Residential/FiOSInternet/Plans/Plans.htm, accessed September 5, 2009.
} 
technologies and bandwidths would be seen as imperfect substitutes such that customers have an elasticity of substitution less than infinity. (Chiang 1984, p. 425) If the degree of heterogeneity is not large, then compiling the products into a single measure does cause errors, but the errors should not be large. There are at least two methods for determining the degree of heterogeneity. One method is to adopt the approach for market definition used in antitrust analysis. That is to say we could perform a standard SSNIP analysis, where SSNIP stands for the test of Small but Significant and Non-transitory Increase in Price. This method examines whether the price of a good could profitably be raised by a hypothetical monopolist. If this rise in the price of a good over a year creates a significant shift of buyers to another good, then the two goods are in the same market. The SSNIP test is repeated with an ever expanding definition of the market until the hypothetical price increase is unprofitable, at which it is concluded that the market definition being tested is the true market. Once the market is defined, analysts examine whether there is market power by studying market concentration, profitability (to see whether there are supernormal profits), barriers to entry and competition, and the like.

For example, if we were to consider whether one measure of broadband, say DSL at 10 mbps, was a substitute for cable modem at 10 mbps we would consider increasing the price for DSL at 10 mbps by 10 percent and test to see if customers would respond to the price increase by migrating to cable modem at 10 mbps. If enough customers would migrate such that the 10 percent price increase was unprofitable, then 10 mbps cable modem and 10 mbps DSL are effectively substitutes and are therefore in the same market. Conversely, if the price increase was profitable, then the two broadband modes would be in different markets. A similar analysis could be performed for various broadband speeds. 
Another approach to testing the substitutability of various broadband modes is to examine the diversion ratio, which relates cross-price elasticities of demand with own-price elasticities of demand and with output. ${ }^{14}$ Several studies provide estimates of demand elasticities for broadband. In a study of Europe, Cardona, Schwarz, Yurtoglu and Zulehner (2007) find similar demand elasticities for various broadband technologies and speeds, leading them to conclude that the modes and speeds are in the same market. In a study of the price elasticity of demand for broadband in the United States, Rappoport et al. (2001) found that demand for broadband via cable modems was price inelastic, but that demand for DSL was price elastic. The study also found that DSL and cable modems were substitutes and so attributed the differences in own-price elasticities to differences in penetration. Crandall, Sidak, and Singer (2002) updated the Rappoport et al. study and found that the elasticities had not changed substantially. But in their own follow-up study, Rappoport et al. (2002) found that demand for the services was becoming more price inelastic, perhaps indicating either increasing penetration or that the services were becoming more essential. Ida and Kuroda (2006) examined the demand for broadband services in Japan. They found that the demand for ADSL in Japan was price inelastic and that the demand for cable modem and fiber to the home was price elastic, perhaps because of the dominance of ADSL in Japan (a finding consistent with the analyses of Rappoport et al. (2001, 2002)).

Lacking price data that could be used to examine the cross-price elasticities or diversion ratios, Hauge, Jamison, and Marcu (2009) try a different approach. They compare characteristics

\footnotetext{
${ }^{14}$ When two goods are substitutes the cross elasticity of demand is positive, so that as the price of one good goes up the demand for the other increases. This is represented as the percentage change in demand for the first good that occurs in response to a percentage change in price of the second good. The diversion ratio quantifies how much of the displaced demand for one product switches to the other product. It is measured by the ratio of the crosselasticity to the own-elasticity multiplied by the ratio of demands, and can be interpreted as the fraction of demand for one good that treats the other good as its next best option (i.e., the number of consumers who would consider the goods to be their first and second choices).For additional details on the usefulness of this measure see: http://www.usdoj.gov/atr/public/speeches/shapiro.spc.htm.
} 
of customers in Portugal who purchase fixed broadband to those who purchase mobile broadband. They find some differences among consumers, ${ }^{15}$ but not many, indicating that mobile and fixed could be substitutes for each other. The finding is not conclusive, however, because the similarity in customer types also could mean that the modes are complements; that is to say that it could be the case that once a customer begins using fixed broadband, that customer might find it important to also have mobile broadband if the customer's lifestyle or career makes it important to carry broadband access with him or her. The Hauge-Jamison-Marcu approach can be used to determine if different broadband modes are not substitutes, but it cannot by itself demonstrate that they are substitutes.

\section{Broadband Indices}

Broadband indices have become popular for the media and politicians as simple metrics that they can interpret as indicators of a country's status with respect to broadband development. However, these indices deceive rather than reveal. The OECD's popular broadband penetration rankings have been criticized widely. Wallsten (2008), for example, explains that the rankings are distorted by differences in household size across countries, that they miss workplace connections, that they are based on data that are inconsistently reported across countries and over time, and that they omit quality differences. Further, the OECD reports overlook relevant data such as subscription for mobile broadband, the fastest growing mode of connectivity in many countries. Ford, Koutsky, and Spiwak (2008) also find numerous deficiencies in the OECD index and demonstrate that the index's rankings lead to erroneous conclusions because the index fails

\footnotetext{
${ }^{15}$ They find that higher income and more years of formal education are the primary consumer characteristics that lead to the choice of mobile broadband over fixed broadband.
} 
to account for variations in household size, geographic and economic endowments, and incomplete data. The ITIF remedies some of the deficiencies of the OECD index by factoring in household size, speed and price.

These traditional broadband indices mislead rather than reveal because they fail to take into consideration the usefulness of broadband by not differentiating adoption and usage. Beard, Ford, and Spiwak (2009) take a step towards remedying this deficiency with their Broadband Adoption Index (BAI), which relates different forms of network access technology to consumer and societal value. The index seeks to compare a country's achieved net value (net consumer surplus plus profit plus social premia ${ }^{16}$ ) from broadband consumption to its theoretical optimum, thus creating an index number that is less than one if broadband is over or under consumed, but equal to one if broadband is optimally consumed. Countries could be compared according to the index. The BAI is data intensive and requires complete knowledge of demand functions and production costs. Such information is always lacking, making it difficult to implement the BAI in practice. In the next section we describe an approach that is less information intensive and that can be used to deconstruct the sources and impacts of shortfalls in broadband availability and uptake.

\section{Identifying Constraints}

An important question for policy makers and other stakeholders is whether broadband availability or adoption are constraining the achievement of societal goals, such as consumer satisfaction, economic growth, education, and the like. A more basic question then is, if

\footnotetext{
${ }^{16}$ Beard, Ford, and Spiwak (2009, p. 36) indicate that social premia include "productivity growth, reductions in transactions costs, improvements in market organizations, improved social and political discourse, more efficient education, and so forth.” But as Holt and Jamison (2008) explain, these social premia are private values and so should be reflected already in the demand for the broadband services.
} 
broadband availability or adoption are constraining achievement, what is constraining broadband?

There are at least four reasons broadband availability or adoption may be a binding constraint on a societal goal. One reason is that even if markets are functioning well, there might be externalities that result in under-consumption of broadband. Atkinson (2007) posits three externalities that he believes lead to market failure in broadband in the United States. The first is network externalities, whereby a consumer does not purchase broadband because it is not worth the price to him, and he fails to take into consideration the net social benefit that would arise from his participation in the broadband network. Atkinson argues that such externalities exist, but he confuses network externalities with network effects. Positive network effects exist when network value increases as more people subscribe to the network. But these effects are externalities only if they are not internalized by the pricing mechanism, which, Liebowitz and Margolis (1995) explain, network providers generally are able to do.

Atkinson's second externality is what he terms "prosumer," which connotes consumers who also operate as producers by taking over functions that had been provided by service sector employees. Examples include self-service checkouts at grocery stores and airport kiosks. However, these are not externalities because the consumer and producer are both able to factor the costs and values of these actions into their consumption and production decisions.

“Competitiveness externalities” are Atkinson’s final broadband externality. His argument is that producers of information and communications technology (ICT) hardware, software, and services will develop primarily where broadband is already widely available and used. However, as Holt and Jamison (2008) explain, this is not an externality but rather the normal provision of a factor of production. 
A second reason that broadband availability and adoption may be binding constraints on societal goals is that broadband providers may have market power and restrict output. Standard economic theory states that if a firm with market power is unable to engage in perfect price discrimination $^{17}$ it will exercise market power by restricting output. ${ }^{18}$

A third reason that broadband availability and adoption might constrain the achievement of societal goals is if there is an artificial shortage or surplus because of price constraints, such as those imposed by regulatory authorities. A broadband shortage would result if the price were kept below a competitive equilibrium, resulting in the quantity supplied being less than the quantity demanded at the prevailing price. A surplus would result if the price were kept artificially high, resulting in the quantity that customers are willing to purchase being less than what producers want to provide. In either situation, the amount of broadband supplied and purchased would be less than the social optimum.

An explicit regulatory constraint on broadband prices does not exist in the United States because broadband is not subject to price regulation. However, this may change with a more activist FCC and with the Democrat Party controlling Congress and the White House. This potential regulation raises two possibilities. First, if the regulation comes about, then there would be shortages or surpluses if the regulated outcome deviated from market equilibrium. ${ }^{19} \mathrm{~A}$ second

\footnotetext{
${ }^{17}$ Perfect price discrimination is said to exist when the supplier is able to charge each customer the maximum price he or she is willing to pay.

${ }^{18}$ Exercising market power by restricting supply is profitable when increasing supply results in a decrease in prices for already served customers. A firm with market power that can perfectly price discriminate does not have an incentive to restrict supply.

${ }^{19}$ Shortages and surpluses were rarely observed in the days of regulated monopoly for telephone services in part because regulators used rate of return regulation, which in effect ensured operators that they would recover their costs even if the prices charged in a particular market were non-compensatory. Rate of return regulation is unlikely to be sustainable in a competitive or partially competitive environment. This means that regulators would use either some other form of regulation, which would not assure cost recover and so could result in shortages, or rate of return regulation ,and the industry would find competition largely inconsequential, perhaps leading to monopoly.
} 
possibility arises if there is a perceived increased propensity to regulate. Suppliers might respond by avoiding actions that would trigger regulation, such as engaging in price discrimination. The resulting uniform prices could lead to some markets being in disequilibrium. ${ }^{20}$ Suppliers might also respond by raising prices in anticipation of regulation if the suppliers believe that regulation, in order to demonstrate its legitimacy, would lower prices. The higher pre-regulation prices would result in a surplus and the lower post regulation prices could result in a shortage.

A fourth reason that broadband availability and adoption might constrain the optimal achievement of social objectives is that there might be a pure market failure, i.e., a situation in which consumers and producers are unable to use the information they would like in making their economic choices. For example, Atkinson (2007) argues that there is a market failure for broadband because consumers lack knowledge about its benefits. Garcia (2009) explains two other potential challenges to broadband availability and adoption, namely too low of market shares and inefficient operations. The market share concern is similar to the destructive competition concern that contributed to the thinking that utilities are natural monopolies, namely that competition may not be sustainable because marginal costs are very low relative to fixed costs (Sharkey 1982 pp. 14-15), but it also relates to the market power issue previously discussed because situations could arise where the number of firms that can profitably enter a market is limited because of the magnitudes of the potential entrants' fixed costs. The inefficiency problem could arise if competition is weak and economic regulation does not provide incentives for operators to be X-efficient.

Given these reasons for possibly suboptimal broadband penetration, it now must be determined if suboptimal broadband penetration exists. There are at least four ways of

\footnotetext{
${ }^{20}$ The uniform prices could result in some geographic areas or customer groups paying prices that are higher or lower than what the operator would find optimal if the operator could price discriminate.
} 
determining whether broadband penetration is suboptimal. ${ }^{21}$ One approach is to test for market power. The standard approach for identifying market power is to first define the market using the SSNIP test and then, once the market is defined, to look for the exercise of market power and for factors that allow market power to persist.

A second approach to determining whether broadband penetration is suboptimal is the mapping method used by organizations such as Connected Nation. Connected Nation uses provider and customer data on the availability of broadband to identify service gaps, which could include situations where potential customers do not have broadband available to them even though they would be willing to pay prices that would make the service commercially viable. If such uneconomic gaps are found and if current service providers are unwilling to supply the gaps, then it could be that these operators are exercising market power, that regulated prices are leading to shortages, or that there is a market failure because of imperfect information or other institutional shortcomings.

A third approach, called the production function approach, examines the optimality of customers' purchases of broadband by comparing the marginal value of broadband to its marginal costs. This might be done at a societal level by comparing broadband costs to the value of its contributions to services, such as education and health care. If education systems, health care providers and the like were able to optimally combine inputs, then using standard optimization analysis we would expect that these customers would purchase an amount of broadband such that the negative price ratio of broadband and an alternative input to be equal to the marginal rate of substitution of the two inputs. If upon examining the production function and input prices we found that the marginal rate of substitution of broadband for the alternative input

\footnotetext{
${ }^{21}$ We set aside the issue of externalities because it does not appear that such externalities actually exist or that, if they do exist, that they are not outside of the range of normal experiences for a functioning economy.
} 
was greater than the negative ratio of the price of broadband to the price of the other input, then it would appear that broadband is being underused, implying that there was a shortage. A difficulty in this approach is defining the value of the output. If the output is a market commodity, such as health care provided by a private medical practice, then market prices can be used. But generally services such as education are government services and so do not have a market price. In such instances proxy values, such as prices for private education of comparable quality could be used. The production function approach can also be applied to commercial businesses using the same approach.

The production function approach could be used for consumers using (4). The left hand side of (4) represents the marginal rate of substitution between two market products in the consumer's function for producing utility. The right hand side represents price ratios. If (4) is not an equality in practice when broadband is one of the market products, then consumers are either under consuming or over consuming broadband.

The production function approach would apply if regulated prices led to a shortage of broadband $^{22}$ or if there was a market failure. However, it is difficult at best to detect a market failure with this approach because the analysis requires knowledge of the actual production function and market information that actual market participants are unable to find.

Our fourth approach remedies some of the shortcomings of the production function approach. This method of determining if broadband penetration is not optimal is an extension of Carlin, Schaffer, and Seabright (2007), which is called the shadow price approach. This approach constructs a model using shadow prices to examine constraints that broadband availability might

\footnotetext{
${ }^{22}$ If the issue were a surplus of broadband, the market price would reflect demand so that the negative price ratio would equal the marginal rate of substitution.
} 
have on societal objectives. ${ }^{23}$ To illustrate, we begin with a simple 1-period model of a benevolent social planner who uses a private good and broadband to produce a social good, for example, economic growth. The private good is a composite of all resources except the broadband inputs of interest. Our unit of observation is an organization that consumes broadband (in some applications this might be a country). The variables that vary at the level of the organization are indexed by $i$. To be specific, we have two inputs: our composite resource, $R$, and broadband, $B$. Our social output is $W$. The supply of broadband is constrained to be no more than a certain amount, $\bar{B}$. We assume a Cobb-Douglas production process such that

$$
W_{i} \equiv F\left(R_{i}, B_{i}\right)=A_{i} R_{i}^{\alpha} B_{i}^{1-\alpha} .
$$

The objective function is

$$
\max _{R_{i}, B_{i}} W_{i}-r R_{i}-c B_{i}
$$

where $r$ is the price of $R_{i}, A_{i}$ is a scalar, and $c$ is the price of $B_{i}$. The broadband constraint is $B_{i} \leq \bar{B}$. The social planner's maximization problem is

$$
\max _{R_{i}, B_{i}} L_{i} \equiv A_{i} R_{i}^{\alpha} B_{i}^{1-\alpha}-r R_{i}-c B_{i}+\lambda_{i}\left(\bar{B}-B_{i}\right) \text {, }
$$

where $\lambda_{i}$ is the Lagrangian multiplier (i.e., the shadow price). When the broadband constraint binds, the multiplier is

$$
\lambda_{i}=\frac{\partial L_{i}}{\partial \bar{B}}=(1-\alpha) A_{i}\left(\frac{R_{i}}{\bar{B}_{i}}\right)^{\alpha}-c .
$$

\footnotetext{
${ }^{23}$ The shadow price is the value of the Lagrange multiplier at the optimal solution, which means that it is the infinitesimal change in the objective function arising from an infinitesimal change in the constraint. When a market price does not exist (or cannot be found) for a particular good, a value must be imputed to that good. In the optimal solution, consumers purchase only those goods for which the imputed values are exactly equal to their respective prices. (Chiang 1984, pp. 696-700).
} 
Carlin, Schaffer, and Seabright (2007) develop a survey instrument that identifies the properties of $\lambda_{i}$. If through analysis of the survey results $\lambda_{i}$ is found to be increasing in $A_{i}$, decreasing in $\bar{B}$, and decreasing in $c$, then broadband availability and adoption is a binding constraint on society.

\section{Conclusion}

In this paper we examine methods of broadband measurement, with particular emphasis on techniques for determining whether broadband availability and adoption are optimal. We identify four methods for identifying the suboptimal situation. These include tests for market power, market surveys, examination of production functions and prices, and analyzing shadow prices. All of these methods utilize broadband measures that one would find in operators' service offerings, and therefore should serve as viable options in the process of developing appropriate broadband measurement techniques. 


\section{References}

Atkinson, Robert D. June 2007. The Case for a National Broadband Policy. The Information and Technology and Innovation Foundation, available at http://www.itif.org/files/CaseForNationalBroadbandPolicy.pdf.

Bauer, Johannes M., Jun Hyun Kim, and Steve Wildman. 2003. Broadband uptake in OECD countries: Policy lessons and unexplained patterns. Paper prepared for presentation at the European Regional Conference of the International Telecommunications Society, Helsinki, Finland.

Beard, T. Randolph, George S. Ford, and Larry J. Spiwak. 2009. "The Broadband Adoption Index: Improving Measurements and Comparisons of Broadband Deployment and Adoption.” Phoenix Center Policy Paper Number 36.

Cardona, Mélisande, Anton Schwarz, B. Burcin Yurtoglu, and Christine Zulehner. 2007. Demand estimation and market definition for broadband Internet services. Available at http://ssrn.com/abstract=1081261.

Carlin, Wendy, March Schaffer, and Paul Seabright. 2007. "Where are the real bottlenecks? Evidence from 20,000 firms in 60 countries about the shadow costs of constraints to firm performance.” Department of Economics, University College of London.

Cava-Ferreruela, Inmaculada and Antonio Alabau-Munoz. 2006. Broadband Policy Assessment: A Cross-national Empirical Analysis, Telecommunications Policy 30(8): 445-463.

Chiang, Alpha C. 1984. Fundamental Methods of Mathematical Economics. Third Edition. New York, New York: McGraw-Hill Book Company.

Crandall, Robert, William Lehr, and Robert Litan. 2007. The Effects of Broadband Deployment on Output and Employment: A Cross-Sectional Analysis of U.S. Data. Issues in Economic Policy, The Brookings Institute, No. 6, 1-34, available at http://www3.brookings.edu/views/papers/crandall/200706litan.pdf.

Crandall, Robert, J. Gregory Sidak, and Hal Singer. 2002. The empirical case against asymmetric regulation of broadband Internet access. Berkeley Law and Technology Journal 17(1): 953-987.

Ford, George S., and Thomas M. Koutsky. 2005. Broadband and Economic Development: A Municipal Case Study from Florida. Applied Economic Studies, 1-15. See also Ford, George S and Thomas M. Koutsky (2005). Broadband and Economic Development: A Municipal Case Study from Florida, Review of Urban and Regional Development Studies 17(3): 216-229.

Ford, George S., Thomas M. Koutsky, and Lawrence Spiwak. 2008. The Broadband Efficiency Index: What Really Drives Broadband Adoption Across the OECD? Phoenix Center Policy Paper Number 33. 
Garcia, Raul. 2009. State Government Intervention in Financing Broadband and Wireless Infrastructure. Presentation at the Wireless U Communications Policy Seminar, San Diego, CA.

Gillett, Sharon, William H. Lehr, Carlos Osorio, and Marvin Sirbu. 2006. Measuring Broadband's Economic Impact. Final report, Prepared for the U.S. Department of Commerce, Economic Development Administration, available at http://www.eda.gov/ImageCache/EDAPublic/documents/pdfdocs2006/mitcmubbimpactreport_2 epdf/v1/mitcmubbimpactreport.pdf.

Hauge, Janice, Mark Jamison, and Mircea Marcu. 2009. Scientific Research Project Coordinated by ICP-ANACOM and ANATEL with a Focus on Mobile Broadband. PURC Working Paper, Department of Economics, University of Florida.

Holt, Lynne and Mark A. Jamison. 2008. Broadband and contributions to economic growth: Lessons from the U.S. Experience. PURC Working Paper, Department of Economics, University of Florida.

Hu, Wei-Min and James Prieger. 2008. The Timing of Broadband Provision: The Role of Competition and Demographics, in Yogesh and K. Dwivedi, et al. (Eds.), Handbook of Research on Global Diffusion of Broadband Data Transmission, Vol. 1, 241-259, Hershey, PA: IGI Global.

Ida, Michiru and Yoshiyuki Kuroda. 2006. Discrete choice analysis of demand for broadband in Japan. Journal of Regulatory Economics 29(1): 5-22.

Lee, Sangwon, and Mircea Marcu. 2008. An Empirical Analysis of Fixed and Mobile Broadband Diffusion. Under review and available from the authors at mircea@ufl.edu.

Liebowitz, S. J., and Stephen E. Margolis. 1995. “Are Network Externalities a New Source of Market Failure?” Research in Law and Economics, 17: 1-22.

Michael, Robert T. and Gary S. Becker. 1973. On the New Theory of Consumer Behavior. The Swedish Journal of Economics 75(4): 378-396.

Prieger, James. 2003. The supply side of the digital divide: Is there equal availability in the broadband internet access market? Economic Inquiry 41(2): 346-363.

Rappoport, Paul, Donald Kridel, Lester Taylor, and James Alleman. 2001. Residential Demand for Access to the Internet. In Gary Madden (Ed.), Emerging Telecommunications Networks: The International Handbook of Telecommunications Economics, Volume II., Edward Elgar Publishers, Cheltenham, UK, pp.1-20.

Rappoport, Paul, Donald Kridel, and Lester Taylor. 2002. The Demand for Broadband: Access, Content, and the Value of Time. in Robert W. Crandall and James H. Alleman, Broadband: Should We Regulate High-Speed Internet Access? Washington, DC: The Brookings Institution. 
Sharkey, William W. 1982 The Theory of Natural Monopoly. Cambridge: Cambridge University Press.

Vilbert, Frank. 2007. The Rise of the Unelected: Democracy and the New Separation of Powers. Cambridge: Cambridge University Press.

Wallsten, Scott. 2008. Understanding Broadband Comparisons. Technology Policy Institute. 